\title{
İtalyanca ve Türkçe Belirsiz Nicelik İfadelerinde Adların Kullanımı Üzerine Bir İnceleme
}

\author{
Sadriye GÜNEŞ 1
}

\begin{abstract}
$\ddot{O} \mathbf{z}$
Evrensel kavramlardan biri olan nicelik kavramı, insanın düşünme sürecinde geniş yer alan çok boyutlu bir kategoridir. Dilbilimde de araştırma konusu olan nicelik, belirli ve belirsiz olmak üzere iki türe ayrılır ve dilde farklı şekillerde ifade edilir. Belirli nicelik sayılarla, formüllerle ve sembollerle ifade edilirken belirsiz niceliğin ifadesinde çeşitli dilbilgisel ve sözcüksel araçlar kullanılır. Sözcüksel seviyede nicelik ad, sıfat, zarf, eylem vb. sözcük türleri ile ifade edilir. Çeşitli dillerde belirsiz nicelik ifade etmede adların yaygın olarak kullanıldı̆̆ı görülmüştür. Gerçek anlamları somut varlıklar ifade eden bu adlar başka varlık ya da kavram adlarıyla bir araya getirilerek kullanıldığında anlam kaymasına uğrayarak belirsiz nicelik ifade etme araçlarından biri haline gelir. Adların yer aldığı nicelik ifadeleri, varlık veya kavramlardan oluşan belirsiz bir çokluğu ya da belirsiz bir azlığı ifade ederken, aynı zamanda bunları yoğunluk, düzenlilik, hareketlilik gibi bazı nitel belirtilere göre de tanımlar, konuşucuların öznel değerlendirmesini ve duygularını yansıtır. Belirsiz nicelik ifadeleri diller arası benzerlikler göstermekte birlikte ürünü oldukları ulusa ve kültüre özgü özellikler taşımaktadır. Bu çalışmada, adların kullanıldığı İtalyanca ve Türkçe belirsiz nicelik ifadeleri, adların yer aldığı anlamsal alanlar, anlamları ve yapıları açısından karşılaştırmalı olarak incelenmiştir. Giriş bölümünde nicelik kavramı, nicelik ifadelerinde adların kullanımı ve yer aldıkları anlamsal alanlar açıklanmıştır. Kullanılan yöntemler belge tarama ve karşılaştırmalı tanım çözümlemesi, anlamsal ve yapısal karşılaştırma olarak belirtilmiştir. Belirlenen İtalyanca ve Türkçe nicelik ifadeleri bulgular bölümünde aktarılmış, yorumlar bölümünde ise anlam ve yapı açısından karşılaştırmalı olarak ele alınmışlardır. Elde edilen sonuçların yabancı dil olarak İtalyanca ve Türkçe öğretimine ve kültürlerarası çalışmalara katkı sağlayacağı düşünülmektedir.
\end{abstract}

Anahtar sözcükler: Belirsiz nicelik, İtalyanca, Türkçe, adlar.

\section{A Review of The Use of Nouns in Italian and Turkish Indefinite Quantity Expressions}

\begin{abstract}
The concept of quantity is a multidimensional category that takes place in the human thinking process. In linguistics, definite quantity is expressed in terms of numbers, formulas and symbols, whereas numerous grammatical and lexical means are used to express indefinite quantity. When indefinite quantity expressions are investigated, nouns are found to be commonly used in expressing quantity. Those nouns whose real meanings express concrete entities, transform into tools for expressing indefinite quantity by undergoing semantic shifts when used with other conceptual words. Indefinite quantity expressions show similarities between languages, even though they carry the specific natural and cultural characteristics. In this study, Turkish and Italian indefinite quantity expressions, in which nouns are used, have been studied comparatively in terms of semantic fields, meanings and structures. In the introductory part, the definition of the concept of quantity, the use
\end{abstract}

Dr. Öğr. Üyesi, İstanbul Üniversitesi, Edebiyat Fakültesi, Batı Dilleri ve Edebiyatları Bölümü, sadriye.gunes@istanbul.edu.tr [Makale kayıt tarihi: 7.3.2018-kabul tarihi: 14.4.2018] 
of nouns in quantity expressions, and the semantic fields in which they appear are discussed. The methods employed are document scanning and comparative definition analysis, semantic and structural comparison. Based on the conducted screening of Italian and Turkish descriptive dictionaries and the analysis of the definitions, indefinite quantity expressions in which nouns are used were identified and presented in the findings section under two headings: indefinite multitude and indefinite fewness expressions. The structural and semantic comparison of the quantity expressions examined is covered in the comments section. It is hoped that the results obtained will contribute to the teaching of Turkish and Italian as a foreign language, and intercultural studies.

Key words: Indefinite quantity, Italian, Turkish, name.

\section{Giriş}

Evrensel kavramlardan biri olan nicelik kavramı, insanın düşünme sürecinde geniş yer alan çok boyutlu bir kategori olması nedeniyle birçok bilimde olduğu gibi dilbilimde de araştırma konusudur. Belirli ve belirsiz olmak üzere iki türe ayrılan nicelik, dilde farklı şekillerde ifade edilir. Belirli nicelik sayılarla, formüllerle ve sembollerle ifade edilirken belirsiz niceliğin ifadesinde çeşitli dilbilgisel ve sözcüksel araçlar kullanılır. Bu nedenle nicelik birçok dilbilimsel araştırmaya konu olmuştur. Alanda yapılan araştırmalara örnek olarak Akulenko ve diğerlerinin (1990) çağdaş Avrupa dillerinde nicelik kategorisi; Galich’in (2002) Almancada niceliğin ifadesi; Aksenova'nın (2014) İngilizcede ve Rusçada belirsiz niceliğin sözcüksel seviyede ifadesi; Alekseyeva'nın (2003) İngilizcede belirsiz niceliğin adlarla ifadesi; Bordyugova'nın (2015) Fransızcada ve Rusçada belirsiz azlık ifade eden adların dilbilgisel özellikleri; Rahilina ve Su-Hyon'un (2009) Rusçada belirsiz niceliğin sözcüksel seviyede ifadesi; Kochergo'nun (2014) Belarusçada belirsiz nicelik ifadelerinde metaforların kullanımı; Sergeyev’in (1996a) niceliğin dilde metaforlarla ifadesi üzerine yaptıkları çalışmalar gösterilebilir.

Çeşitli dillerde yapılan araştırmalar incelendiğinde, sözcüksel seviyede belirsiz niceliğin ifadesinde adların yaygın olarak kullanıldığı görülmektedir. Bu ifadelerin bir yandan diller arası benzerlikler gösterdikleri, diğer yandan ürünü oldukları ulusa ve kültüre özgü özellikler taşıdıkları belirlenmiştir. Alandaki araştırmalar ışığında İtalyanca Sözcükbilim dersinde kavramların dilde ifadesi üzerine yapılan çalışmalarda, farklılık göstermeleri nedeniyle İtalyanca ve Türkçe belirsiz nicelik ifadelerinde adların kullanımı üzerine karşılaştırmalı bir inceleme gereksinimi ortaya çımıştır. Bu gereksinim doğrultusunda yapılan araştırmadan elde edilen bulguların ve ulaşılan sonuçların yabancı dil olarak İtalyanca ve Türkçe öğretimine, bu dillerdeki çeviri ve kültürlerarası çalışmalara katkı sağlayacağı düşünülmektedir.

Giriş bölümünde nicelik kavramı, nicelik ifadelerinde adların kullanımı ve anlamsal alanları kısaca açıklanmaktadır. Daha sonra yöntem, bulgular, yorum ve sonuç bölümlerine yer verilmektedir.

\subsection{Nicelik Kavramı}

Nicelik, artıp eksilebilen, sayılabilen, ölçülebilen bir büyüklüğün ölçme ve hesaplama işlemleriyle yapılan bir karşılaştırmanın sonucunda kesin ya da yaklaşık olarak ifade edilen değeridir (Panfilov, 1977, s. 158), ne kadar, ne büyüklükte sorularının karşılığıdır. Dünyayı algılama, öğrenme ve yansıtma süreçlerinde varlıkların, maddelerin vb. oluşturdukları nicelikler matematiksel, kesin ve nesnel bir şekilde ya da matematiksel olmayan, yaklaşık ve belli ölçüde öznel bir şekilde ifade edilebilir (Galich, 
2002, s. 24). Nicelik, insanın düşünme sürecinde geniş yer alan çok boyutlu bir kategoridir, bu nedenle dilbilimde de araştırma konusudur (Kuzina, 2014, s. 108).

Bilimsel dilde niceliğin kesin bir şekilde ölçülmesi ve ifade edilmesi önemlidir (Ryabceva, 2000, s. 108), bu nedenle nicelik kesin ve net bir şekilde sayı veya sembollerle, nicel işlemler de matematiksel formüllerle ifade edilir. Doğal dilde nicelik ele alındığında insanoğlunun yalnızca ölçülebileni değil, ölçme işleminin uygulanamadığı şeyleri de ölçmek istediği, bir başka deyişle duygu ve düşüncelerin derinliğini, olumsuzlukların yarattığı zararların büyüklüğünü belirlemek istediği görülmektedir. Varlıklar ve olaylar, fikirler ve kavramlar, özellikler ve nitelikler, düşünceler, izlenimler ve tahminler, iyi veya kötü davranışlar dünyası nicel değerlendirme konusu olduğunda ortaya çıkan duygular insanı sürekli olarak abartmaya ya da küçümsemeye, gerçek bir şekilde değerlendirme mümkün olmasa da çokluk veya azlık hakkında konuşmaya iter. Dolayısıyla ölçme sisteminde sapmalar meydana gelir, nicelik niteliğe dönüşür, nitelik de nicel birimlerle ölçülmeye başlar. Doğal dilde kesin bir şekilde ölçülemeyen niceliğin değerlendirilmesi öznel hale gelir ve buna dayalı olarak belirsiz nicelik ve yaklaşık değerler ifade etme sistemleri geliştirilir (Arutyunova, 2005, s. 20); belirsiz nicelik kesin sayılarla değil de, bir çeşit tahmini eşdeğerleriyle ifade edilir (Ryabceva, 2000, s. 108).

Nicelik kavramı doğal dilde çeşitli dilbilgisel ve sözcüksel araçlarla ifade edilir. Dilbilgisel olarak niceliğin ifadesi dilin sesbilimsel, biçimbilimsel, sözcüksel ve sözdizimsel seviyelerindeki birimleriyle gerçekleştirilir (Aksenova, 2014, s. 13). Sesbilimsel seviyede sözcüklerdeki seslilerin uzatılması ya da kısaltılması; biçimbilimsel seviyede tekil-çoğul sayıların, karşılaştırma derecelerinin, kişi eklerinin, sözcük yapımında nicelik ifade eden çeşitli biçimbirimlerinin kullanımı; sözcüksel seviyede nicelik veya nicelik-nitelik anlamı taşıyan çeşitli sözcüklerin kullanımı; sözdizimsel seviyede görülen belirli yapılar ve sözcük tekrarları nicelik ifade etme yöntemleridir (Kuzina, 2014, ss. 111-113). Sözcüksel seviyede nicelik tüm sözcük türleri ile, örneğin varlıkların niceliği adlarla, niteliklerin niceliği sıfat ve belirteçlerle, süreçlerinin niceliği eylemle ifade edilir (Turaeva ve Birenbaum, 1985).

Çalışma konusu çerçevesinde belirsiz nicelik ifadelerinde adların kullanımı daha ayrıntılı olarak ele alınacaktır.

\subsection{Nicelik İfadelerinde Adların Kullanımı}

Gerçek anlamları somut varlıklar ifade eden bazı adlar, başka varlık veya kavram adlarıyla bir araya gelerek oluşturdukları yapılarda anlam kaymasına uğrayarak ve kısmen dilbilgisel özellikler kazanarak belirsiz nicelik ifade eder duruma gelmektedir. Adların yer aldığı bu yapılar öznel bir değerlendirme içerir ve çok fazla anlamında belirsiz bir çokluğu ya da çok az anlamında belirsiz bir azlığı ifade eder (Aksenova, 2014, s. 13). Bu tür adlara ilişkin somut örnekler şöyle verilebilir:

İtalyancada bir doğa olayı adı olan pioggia (yağmur) sözcüğünün, yine ad olan errore (hata) sözcüğü ile bir araya gelerek oluşturduğu pioggia d'errori (hata yağmuru) şeklindeki yapı (ZIN, s. 1318), hatalardan oluşan belirsiz bir çokluk anlamında kullanılır. Aynı şekilde Türkçede ad olan yağmur sözcüğünün, yine ad olan para sözcügü ile oluşturduğu para yağmuru şeklindeki yapı (TDKG) paradan oluşan belirsiz bir çokluğu ifade eder.

İtalyancada insan bedeninin bir parçasının adı olan palmo (avuç) sözcüğünün, yine ad olan terra (arazi) sözcüğü ile oluşturduğu un palmo di terra (bir avuç arazi) şeklindeki yapı (GAB) az miktardaki araziden oluşan belirsiz bir niceliği ifade eder. Aynı şekilde Türkçede ad olan avuç sözcüğünün, yine ad olan insan 
sözcüğü ile oluşturduğu bir avuç insan şeklindeki yapı (TDKG) az sayıda insandan oluşan belirsiz bir niceliği ifade eder.

Ele alınan yapılardaki pioggia/yağmur ve palmo/avuç sözcükleri gerçek anlamlarından uzaklaşarak sırasıyla belirsiz bir çokluk ve belirsiz bir azlık, başka bir ifadeyle nicelik eder duruma gelmişlerdir. Verilen örneklerde görüldüğü üzere gerçek anlamları varlık ifade eden adlar, oluşturdukları yapılarda gerçek anlamlarından uzaklaşarak başka bir varlığın ya da kavramın niceliğini tanımlar duruma gelmişlerdir (Aksenova, 2014, s. 14).

Sergeyev (1996a, s. 63), sözcüksel seviyede nicelik ifade eden adların ve bu adların başka adlarla oluşturdukları yapıların metaforlaştığını ileri sürerek konuyu farklı bir açıdan ele almıştır. Nicelik ifade eder duruma gelen yağmur, çı̆̆, deniz, göl, dă vb. gibi adların ve gerçek anlamları da nicelik ifade eden, kap veya büyük kap olarak adlandırılan sepet, vagon vb. gibi adların anlam kayması neticesinde nicelik metaforlarına dönüştüğünü belirtmiştir. Yazara göre genel dilsel metaforlar olarak tanımlanan nicelik metaforları nesneleri, olguları ve olayları nicel olarak betimler, duyguları ifade etme araçlardır; örn., insan seli, para yağmuru vb. şeklindeki ad temelli metaforlar varlıkları veya gerçekleşen olayları miktarı, boyutu, yüksekliği, hacmi vb. fiziki değerleriyle yapılan benzerliklere dayalı olarak oluşturulmuş; niceliğin metaforlarla ifadesi aynı zamanda niteliğin de ifadesidir.

Nicelik ifadelerinde ad kullanımının etkili bir anlatım aracı olduğuna ilişkin görüşler belirtilmiştir. Sergeyev (1996b), nicelik ifade eden ad temelli metaforların reklam dilindeki etkisine değinmiştir. Lukyanova (1986), adların yer aldığı belirsiz nicelik ifadelerindeki etkili anlatımı sağlayan imgeselliğin, varlıkların ve olayların ortaya çıkış veya değişim dinamikleri; ardı ardına gelmeleri veya düşmeleri; akış halinde gelmeleri; yatay veya dikey yerleşimleri; çağrıştırdıkları derinlik; belli bir düzene göre yerleşimleri; dağınık, karışık veya durağan halleri vb. ile ilgili olduğunu ifade etmiştir.

Rahilina ve Su-Hyon (2009, s. 13), herhangi bir kümenin niceliğini belirten adların, niceliğin yanında bu kümeyi türdeşlik, düzenlilik vb. gibi bazı nitel belirtilere göre de tanımladıklarını belirtmişlerdir. Araştırmacılara göre niceliği ifade edilmek istenilen varlıkların uzunluğu ve yerleşimlerinin yoğunluğu, tekrarlanan eylemlerin belli bir zaman diliminde sıklı̆̆ gibi görsel olarak algılanan çeşitli uzamsal ilişkiler nicel değerlendirmeyi en çok etkileyen unsurlardır. Görsel algılama sonucu bir niceliğin çokluk veya azlık olarak değerlendirilmesinin yanında sözü edilen nitel özellikler de belirtilir (Kuzina, 2014, s. 110).

\subsection{Nicelik İfadelerinde Kullanılan Adların Anlamsal Alanları}

Nicelik ifadelerinde hangi adların kullanıldığını belirleme çalışmalarında Sergeyev (1996a, s. 65) adların izleksel grupları ifadesini kullanırken Rahilina ve Su-Hyon (2009, s. 37) adların geldiği verici ya da anlamsal alanlar ifadesini kullanmışlardır.

Sergeyev'in (1996a, s. 65) tanımlamasına göre nicelik ifadelerinde metaforlara dönüşen adların yer aldığı izleksel gruplar şöyle belirlenmiştir: zincir, spektrum vb. gibi teknik terimler; epidemi vb. gibi tıp terimleri; orman, sürü vb. gibi hayvanlar ve bitki dünyasına özgü sözcükler; yağmur, deniz vb. gibi coğrafya, meteoroloji ve astronomi alanlarına özgü sözcükler; ordu, alay vb. gibi askeri terimler; hanedan vb. gibi eski sözcükler; çevre, piramit vb. geometrik şekil adları; bardak, kaşık vb. gibi günlük yaşamda kullanılan nesne adları. 
Rahilina ve Su-Hyon (2009, s. 37), belirsiz çokluk ifade eden adları; geniş alan ve yüzeyler (deniz, orman vb); dikey nesneler (dă̆, yığın vb.); derin boşluklar (uçurum vb.); kaplar veya büyük kaplar (çuval, araba vb.); çok sayıda öğe içeren kümeler (sürü, ordu vb.); yatay hareket eden kitleler (nehir vb.); havada hareket eden ve düşen kitleler (yağmur, dolu vb.); aniden ortaya çıkan kitleler (çı̆̆ vb.); belirsiz azlık ifade eden adları: küçük ve sınırlı yüzeyler ( $a v u c ̧$ vb.); bir bütünden alınan küçük kitle ve hacimler (damla, lokma vb.); bir bütünden alınan küçük parça veya bölümler (dilim, kırıntı vb.); küçük nesneler (kıl, kaşık vb.) anlamsal alanlarına göre sınıflandırmışlardır.

\section{4. Çalışmanın Amacı}

Çalışmanın amacı İtalyanca ve Türkçe belirsiz nicelik ifadelerinde adların kullanımını karşılaştırmalı olarak incelemektir. Karşılaştırmalı inceleme, belirsiz nicelik ifadelerinde kullanılan adların ait oldukları anlamsal alanlara, anlamlarına, niceliği ifade edilecek varlık veya kavram adlarıyla bir araya gelerek oluşturdukları yapılara göre yapılacaktır. Karşılaştırma sonucunda İtalyanca ve Türkçe belirsiz nicelik ifadelerinde adların kullanımına ilişkin benzerlikler ve farklılıklar belirlenecektir.

Araştırmada elde edilecek olan bulguların ve sonuçların Sözcükbilim ve Çeviri Uygulamaları derslerindeki öğretim etkinliklerinde kullanılması amaçlanmaktadır.

\section{Yöntem}

$\mathrm{Bu}$ araştırmada belge tarama ve karşlaştırmalı tanım çözümlemesi, anlamsal ve yapısal inceleme yöntemleri kullanılmıştır. Çalışmada, konunun genişliği nedeniyle Rahilina ve Su-Hyon'un (2009) nicelik ifade eden adların belirlenmesinde oluşturduğu anlamsal alanlar dikkate alınmış ve bu nedenle anlamsal alan terimi tercih edilmiştir. Alanyazında belirsiz nicelik konusunun metafor açısından da ele alındığı görülmüş, ancak konuya adlar açısından yaklaşılmıştır.

Belge tarama İtalyanca ve Türkçe basılı ve çevrimiçi açılkamalı sözlükler, İtalyanca ve Türkçe derlemler incelenerek yapılmıştır. Önce İtalyanca, daha sonra Türkçe sözlükler incelenmiş ve söz konusu anlamsal alanlara ait olan adların nicelik ifade edip etmediklerine bakılmıştır. Karşılaştırmalı tanım çözümlemesi, belirsiz nicelik ifade eden adların sözlük madde başlıkları altında verilen tanımlar İtalyanca ve Türkçe için karşılaştırılarak yapılmıştır. Nicelik ifade ettikleri belirlenen İtalyanca ve Türkçe adlar bulgular bölümünde verilmiştir. Bulguların sıralamasında belirsiz çokluk ve belirsiz azlık anlamsal alanları gözetilmiş, ilk olarak İtalyanca ad, hemen yanına yan çizgi konulduktan sonra Türkçe karşılı̆̆l, bulunması durumunda bu adların nicelik ifade eden eş anlamlıları da belirtilmiştir. Adların ifade ettikleri nicelik anlamları ve kullanım örnekleri aktarılırken bulundukları kaynaklar gösterilmiştir. Örneğin, geniş yüzeyler anlamsal alanına ait olan İtalyanca mondo sözcüğünden oluşan sözlük madde başlığı incelenmiş, bu başlık altında verilen tanımlar çözümlenmiştir. Ad olarak mondo sözcüğünün "pek çok, büyük nicelik" anlamında, örn., un mondo di problemi (bir dünya sorun) şeklinde kullanıldığı tespit edilmiştir (REP). Mondo sözcügünün Türkçe karşıllğı olan dünya sözcügünden oluşan sözlük madde başlığı incelendiğinde, söz konusu adın "pek çok, büyük nicelik” (TDKG) anlamında, örn., dünya kadar iş (TUD) şeklinde kullanıldığı görülmüştür.

Anlamsal karşılaştırma, adların kullanıldığı İtalyanca ve Türkçe belirsiz nicelik ifadeleri ifade ettikleri anlam, adların ait olduğu anlamsal alanlar, niceliğin yanında belirtilen nitel özellikler, anlam güçlendirmesi açısından ele alınarak yapılmıştır. Yapısal karşılaştırma, İtalyanca ve Türkçe adların niceliği ifade edilecek varlık veya kavram adlarıla bir araya gelerek oluşturdukları söz öbekleri 
şeklindeki yapılar dikkate alınarak yapılmıştır. Bu yapıların tümce içerisinde kullanımı ve işlevleri ele alınmamıştır. Karşlaştırma sonucunda İtalyanca ve Türkçe belirsiz nicelik ifadelerinde adların kullanımında benzerlikler ve farklılıklar belirlenmiştir.

Bulgular bölümünde kaynakları daha kısa bir şekilde göstermek amacıyla İtalyanca için İt.; Türkçe için Tr.; Zingarelli (1996), Vocabolario della lingua italiana için ZIN; Gabrielli (2011), Grande dizionario di italiano için GAB; La Repubblica.it (2011), Dizionario di italiano dalla A alla $Z$ için REP; Corriere della Sera, Dizionario di italiano için COR; TDK Türkçe sözlük (1988) için TDK; TDK çevrimiçi Güncel Türkçe sözlük için TDKG, Aksan, Y. et al. (2012), Construction of the Turkish National Corpus (TNC) Turkçe Ulusal Derlemi için TUD; İtalyanca Corpus CORIS derlemi için CORIS kısaltmaları kullanılmıştır.

Nicelik ifadelerinde kullanılan adların Rahilina ve Su-Hyon'un (2009) oluşturdukları anlamsal alanlar dikkate alınarak belirlenmesi çalışmanın sınırlılıkları oluşturmaktadır.

\section{Bulgular}

İtalyanca ve Türkçe belirsiz nicelik ifadelerinde adların kullanımına ilişkin bulgular belirsiz çokluk ve belirsiz azlık ifadeleri olmak üzere iki başlık altında aktarılmaktadır.

\subsection{Belirsiz Çokluk İfadelerinde Kullanılan Adlar}

Belirsiz çokluk ifadelerinde kullanılan adlar ve bu adların niceliği ifade edilecek varlık veya kavram adlarıyla bir araya gelerek oluşturdukları yapılara ilişkin örnekler aşağıdaki belirtilen anlamsal alanlara göre verilmektedir.

a. Belirsiz Çokluk İfadelerinde Geniş Alan ve Yüzey Adları

mare/ deniz, derya

İt. mare sözcüğünün "geniş alan, büyük miktar" anlamında, örn., un mare d'erba/ gente/ oferte (ot/ insan/ teklif denizi) (GAB) şeklinde; Tr. derya, deniz sözcüklerinin "geniş alan, çokluk, yoğunluk, bir şeyin bol olduğu yer, pek çok” anlamlarında (TDKG), örn. derya gibi bilgi/bir kalabalık (TUD) şeklinde kullanıldığı belirlenmiştir. TDKG sözlüğünde deniz sözcüğünün çokluk ifade ettiği belirtilmiş olsa da kullanım örneklerine rastlanmamıştır.

oceano/ okyanus

İt. oceano sözcüğünün "büyüklüğü ölçülemez nicelik" anlamında, örn., un oceano di folla/ parole/ fango (okyanus dolusu kalabalık/ sözcük/ çamur) (REP) şeklinde kullanıldığı belirlenmiştir. Tr. okyanus sözcüğünün nicelik ifade eden anlamına sözlüklerde rastlanmamış, ancak (TUD) incelendiğinde okyanus dolusu su şeklinde çokluk ifade eden bir ifadeye rastlanmıştır.

mondo/ dünya

İt. mondo sözcüğünün "pek çok, büyük nicelik" anlamında, örn., un mondo di problemi/ cortesie (bir dünya sorun/ nezaket) (REP) şeklinde; Tr. dünya sözcüğünün "pek çok, büyük nicelik" anlamında (TDKG), örn., dünya kadar iş/ zaman (TUD) şeklinde kullanıldığı belirlenmiştir. 
lago/göl

İt. lago sözcüğünün "büyük miktar" anlamında, örn., un lago di sangue/ pensiero (kan/ düşünce gölü) (REP) şeklinde; Tr. göl sözcüğünün nicelik anlamında kullanımına sözlüklerde rastlanmamış olsa da, bir kavga, savaş vb. durumlarda çok kan döküldüğünü ifade etmek için kan gölüne dönmek/ çevirmek (TUD) şeklinde kullanıldığı belirlenmiştir.

foresta, bosco/ orman

İt. foresta, bosco sözcüklerinin “yoğun, çok, birbirine karışmış, gür” anlamında, örn., una foresta/ un bosco di capelli (saç ormanı) (GAB), foresta di pensieri (düşünce ormanı) (CORIS) şeklinde; Tr. orman sözcügünün İtalyanca sözcükle aynı anlamda orman gibi (TDKG), orman saçl (TUD) şeklinde kullanıldığı belirlenmiştir.

b. Belirsiz Çokluk İfadelerinde Dikey Varlık Adları

montagna/ dă̆

İt. montagna sözcüğünün "pek çok" anlamında, bir arada bulunan çok sayıda nesneyi ifade etmek için (GAB), örn., una montagna di libri/ informazioni (bir dağ kitap/ bilgi) (CORIS) şeklinde; Tr. dă̆ sözcüğünün İtalyanca sözcükle aynı anlamda, (TDK, s. 328), örn., dosyalar dă̆ gibi, dă̆ gibi bulaşı, dağlar kadar mesafe (TUD) şeklinde kullanıldığı belirlenmiştir.

mucchio, cumulo, barca/ yığın

İt. mucchio sözcüğünün çok sayıda varlığın bir arada bulunmasını ifade etmek için, örn., un mucchio di persone/ soldi (bir yığın kişi/ para) (GAB); İt. cumulo sözcüğ̈̈nün "birçok, pek çok" anlamında, örn., un cumulo di errori/ sciocchezze (bir yığın hata/ saçmalık); İt. barca sözcüğünün "pek çok" anlamında, örn., una barca di quattrini (bir yığın para) (REP) şeklinde; bu sözcüklerin Türkçe karşllığı olan yığın sözcüğünün "belirsiz çokluk" anlamında (TDKG), örn., yığınla para/ soru, bir yığın öykü (TUD) şeklinde kullanıldı̆̆ı belirlenmiştir.

c. Belirsiz Çokluk İfadelerinde Derin Boşluk Adları

subisso/ uçurum

İt. subisso sözcüğünün "çok sayıda" anlamında, örn., un subisso di regali/ spettatori (bir uçurum hediye/ seyirci) (REP) şeklinde kullanıldığı belirlenmiştir. Türkçede uçurum sözcüğünün olay, olgu, nesnelerin vb. aralarında büyük bir fark ve ayrılığın bulunduğunu belirtmek için, örn., aradaki uçurum, derin uçurum (TDKG), gelir uçurumu, rakamlar arasındaki uçurum (TUD) şeklinde kullanıldığı belirlenmiştir

d. Belirsiz Çokluk İfadelerinde Kap ve Büyük Kap Adları

sacco/ çuval

İt. sacco sözcü̆üünü "çok, pek çok, çok fazla” anlamında, örn., un sacco di gente/ soldi/ tempo (bir çuval insan/ para/ zaman) (ZIN, s. 1563) şeklinde; Tr. çuval sözcüğünün İtalyanca sözcükle aynı 
anlamda, örn., bir çuval dolusu para, çuvallar dolusu ihbar, çuval çuval şeker, bir çuval sevinç (TUD) şeklinde kullanıldığı belirlenmiştir.

vagone, carrozza/ vagon, araba

İt. vagone sözcügünün "büyük miktar" anlamında, örn., un vagone di libri/ sciocchezze (bir vagon kitap/ saçmalık) (GAB) şeklinde; Tr. vagon sözcüğünün "çokluk” anlamında vagon dolusu altın (TUD) şeklinde kullanıldığı; İt. carrozza sözcüğünün nicelik anlamında kullanılmadığı; Tr. araba sözcüğünün "pek çok, fazla" anlamında (TDKG), bir araba lakırdı, arabalar dolusu ürün (TUD) şeklinde kullanıldı̆̆ı belirlenmiştir.

scanalatura/oluk

İt. scanalatura sözcüğünün nicelik anlamında kullanılmadı̆̆ı; Tr. oluk sözcüğünün "pek çok, çok bol ve arası kesilmeden sürekli gelen nicelik" anlamında (TDKG), örn., oluk gibi para akmak, oluk oluk kan akmak (TUD) şeklinde kullanıldığı belirlenmiştir.

grembo/kucak

İt. grembo sözcüğünün nicelik anlamında kullanılmadığı; Tr. kucak sözcüğünün "pek çok, pek bol” anlamında kucak kucak (TDKG), kucak dolusu para/ sevgi (TUD) şeklinde kullanıldığı belirlenmiştir.

palmo/avuç

İt. palmo sözcüğünün çokluk anlamında kullanılmadığı görülmüştür. Tr. avuç sözcüğünün "pek çok" anlamında (TDKG), örn., avuç dolusu para, avuç avuç altın (TUD) şeklinde kullanıldığı belirlenmiş, azlık anlamında kullanımı ise belirsiz azlık ifadeleri başlığı altında verilmiştir.

fascio/tomar

İt. fascio sözcüğünün "yığınla” anlamında, örn., un fascio di documenti/ riviste (bir tomar belge/ dergi) (GAB) şeklinde; Tr. tomar sözcüğünün "pek çok, fazla" anlamında (TDKG), örn., bir tomar para, tomar tomar dolar (TUD) şeklinde kullanıldığı belirlenmiştir.

e. Belirsiz Çokluk İfadelerinde Çok Sayıda Öğe İçeren Küme Adları

esercito/ ordu

İt. esercito sözcügünün "çok sayıda insan, canlı vb., kalabalık" anlamında, örn., un esercito di disoccupati/creditori (işsizler/ alacaklılar ordusu) (GAB) şeklinde; Tr. ordu sözcügünün aynı anlamda, örn., işsizler/ çalışan ordusu (TUD) şeklinde kullanıldı̆̆ı belirlenmiştir.

\section{batteria/ batarya}

İt. batteria sözcüğünün bir arada bulunan, belirsiz sayıdaki aynı ya da benzer unsurları ifade etmek için, örn., una batteria di giocattoli/ test (bir batarya oyuncak/ test) (GAB) şeklinde kullanıldığı; Tr. batarya sözcüğünün nicelik belirtmede kullanılmadığı görülmüştür.

reggimento/ alay 
İt. reggimento sözcüğünün "birçok, pek çok" anlamında (GAB), örn., un reggimento di impiegati/ mensole (bir alay memur/ raf) (CORIS) şeklinde; Tr. alay sözcügünün İtalyanca sözcükle aynı anlamda alay alay, bir alay, bir alay adam (TDKG) şeklinde kullanıldığı belirlenmiştir.

\section{battaglione/ tabur, tümen}

İt. battaglione sözcüğünün "küme, yığın, grup, çok sayıda insan” anlamında (GAB), örn., un battaglione di medici/ nuotatori (bir tabur doktor/ yüzücü) (CORIS) şeklinde; Tr. tabur ve Tr. tümen sözcüklerinin İtalyanca sözcükle aynı anlamda örn., bir tabur okullu kız, tümen tümen insan (TDKG) şeklinde kullanıldığı belirlenmiştir.

branco, gregge, sciame/sürü

İt. branco sözcüğünün "küçümseme" anlamını da katarak bir grubu ifade etmek için, örn., un branco di ladri (hırsız sürüsü); şaka yoluyla düzensiz ve gürültülü bir grubu ifade etmek için, örn., un branco di scolaretti/ stranieri (öğrenci/ yabancılar sürüsü); İt. gregge sözcüğünün bir arada bulunan çok sayıda insanı, pasif ve itaatkar insan topluluğunu ifade etmek için, örn., un gregge di pavidi (korkaklar sürüsü); İt. sciame sözcüğünün birlikte veya düzensiz bir şekilde hareket eden insan veya nesneler için, örn., uno sciame di stranieri/ bambine (yabancı/ çocuk sürüsü) (GAB; CORIS) şeklinde kullanıldı̆̆ı belirlenmiştir. Tr. sürü sözcügünün "birçok, pek çok" anlamında bir sürü, sürü sepet, sürü sürü şeklinde (TDKG), örn., bir sürü dedikodu, sürü sepet genç, bir sürü eleman/ kolaylı/ banka (TUD) şeklinde kullanıldığı belirlenmiştir.

\section{carovana/ kervan}

İt. carovana sözcüğünün şaka yoluyla kalabalık ve gürültülü bir grubu ifade etmek için, örn. una carovana di amici (arkadaş kervanı) (GAB), una carovana di donne/ schiavi (kadınlar/ köle kervanı) (CORIS) şeklinde; Tr. kervan sözcügünün toplu olarak birbiri ardınca gelen şeyleri ya da kalabalık bir grubu ifade etmek için (TDKG), örn., bankalar/ profesyoneller kervanı (TUD) şeklinde kullanıldığı belirlenmiştir.

\section{f. Belirsiz Çokluk Belirten ve Yönlü Hareket Eden Varlık Adları}

torrente, fiume, fiumana/ dere, trmak, nehir

İt. torrente sözcüğünün bir şeyin bol miktardaki akışını ifade etmek için, örn., un torrente di fuoco/ emozioni (ateş/ duygu deresi); İt. fiume sözcügünün "büyük miktarda ve hızlı bir biçimde art arda gelen şeyler" anlamında, örn., un fiume di fango/ chiacchiere (çamur/ dedikodu nehri); İt. fiumana sözcüğünün "özellikle aynı yönde hareket eden çok sayıda insan veya nesne, kalabalık” anlamında, örn., una fiumana di veicoli/ turisti (araba/ turist nehri) (COR; CORIS) şeklinde kullanıldığı belirlenmiştir. Tr. dere, ırmak ve nehir sözcüklerinin nicelik belirtmede kullanılmadığı görülmüştür.

pioggia/ yağmur

İt. pioggia sözcüğ̈̈nün "çokluk, bolluk, çok ve sık düşen veya gelen şeyler” anlamında (GAB), örn., una pioggia di complimenti/ lacrime/ cenere (tebrik/ gözyaşı/ kül yağmuru) (CORIS) şeklinde; Tr. yağmur sözcüğünün "çokluk, bolluk" anlamında (TDKG), örn., hediye/ vergi/ceza yağmuru (TUD) şeklinde kullanıldığı belirlenmiştir. 
grandine/ dolu

İt. grandine sözcüğünün "güçlü ve devamlı bir şekilde bir şey veya bir kimse üzerine düşen varlıklar" anlamında (COR), örn., grandine di proiettili/ insulti/ sassi (dolu şeklinde mermi/ hakaret/ taş) (CORIS) şeklinde kullanıldığı; Tr. dolu sözcüğünün nicelik ifadelerinde kullanılmadığı görülmüştür.

tempesta/ firtina

İt. tempesta sözcügünün “şiddetli ve gürültülü bir şekilde, çok sayıda ve art arda gelen veya düşen şeyler” anlaminda (REP), örn., una tempesta di proiettili/ accuse/ pensieri/ emozioni (mermi/ suçlama/ düşünce/ duygu firtınası) (CORIS) şeklinde kullanıldığı; Tr. firtına sözcüğünün nicelik ifadelerinde kullanılmadığı görülmüştür.

\section{bombardamento/ bombardıman}

İt. bombardamento sözcüğ̈̈nün "çok sayıda, hızlı ve yoğun bir şekilde bir şeylere ya da eylemlere maruz kalma” anlamında (GAB), örn., un bombardamento di accuse/ immagini (suçlama/ görüntü/ bombardımanı) (CORIS) şeklinde; Tr. bombardıman sözcüğünün İtalyanca sözcükle aynı anlamda (TDKG), örn., haber/ reklam/ vergi bombardımanı (TUD) şeklinde kullanıldığı belirlenmiștir.

nugolo/ bulut

İt. nugolo sözcüğünün "herhangi bir şeyden oluşan yoğun yığın" anlamında (COR), örn., un nugolo di avvocati/ aziende/ frecce (avukatlar/ şirketler/ ok bulutu) (CORIS) şeklinde; Tr. bulut sözcüğünün İtalyanca sözcükle aynı anlamda (TDKG) örn., toz/ sivri sinek bulutu şeklinde kullanıldığı belirlenmiştir.

profluvio, diluvio, alluvione, inondazione/ sel

İt. profluvio sözcüğünün "bol miktarda akışkan madde" anlamında, örn., profluvio di lacrime (gözyaşı seli), "çok sayıda insan veya nesne" anlamında, örn., profluvio di gente/ parole (insan/ sözcük seli); İt. diluvio sözcügünün "büyük miktarda herhangi bir şeye maruz kalma" anlamında,, örn., un diluvio di proteste/ critiche (protesto/ eleştiri seli); İt. alluvione sözcügünün "küçümseme" anlamı da katılarak "aşırı, hantal bir nicelik" anlamında, örn., un'alluvione di telefilm/ pubblicità (telefilm/ reklam seli); İt. inondazione sözcüğünün "insan veya bir şeyin yayılması ve bolluğu" anlamında, örn., inondazione di turisti / informazioni (turist/ bilgi seli) (GAB; CORIS) şeklinde; Tr. sel sözcüğünün "hareket halindeki büyük kalabalık, yığın, yoğunluk” anlamında (TDKG), örn. insan seli, sevgi seli (TUD) şeklinde kullanıldı ̆̆ belirlenmiştir.

caterva/ tufan

İt. caterva sözcügünün "çok sayıda insan ya da şeyler" anlamında (GAB), örn., una caterva di gente/ dubbi/ segni (insan/ tereddüt/ işaret tufanı) (CORIS) şeklinde; Tr. tufan sözcüğünün "çok yoğun veya şiddetli bir şey” anlamında (TDKG), örn., heyecan tufanı şeklinde kullanıldığı belirlenmiştir.

massa, folla, ressa, calca/ kitle, küme 
İt. massa sözcüğünün “düzensiz büyük nicelik; insan kalabalığı” anlamında, örn., una massa di legna/ errori/ ascoltatori (odun/ hata/ dinleyici kitlesi); İt. folla, ressa, calca sözcüklerinin "insan kalabalı̆̆ı" anlaminda, örn., una folla/ressa/calca di ammiratori/ candidati (hayran/ aday kitlesi) (GAB), una ressa di nuvole (bulut kitlesi) (CORIS) şeklinde; Tr. kitle, küme sözcüklerinin "belirli işleviyle özellik gösteren büyük insan kalabalı̆̆ı” anlamında (TDKG), örn., bir küme insan, öğrenci/ tüketici/ müssteri kitlesi (TUD) şeklinde kullanıldığı belirlenmiştir.

invasione/ istila

İt. invasione sözcüğünün "çok sayıda öğeden oluşan bir grubun aniden ortaya çıkıp yayılması" anlamında (GAB), örn., l'invasione di spettatori/ messaggi/ merci (seyirci/ mesaj/ mal istilası) (CORIS) şeklinde; Tr. istila sözcüğünün "yayılmak, kaplamak, sarmak, bürümek” anlamında (TDKG), örn., böcek/ turist/ mülteci istilası (TUD) şeklinde kullanıldı̆̆ı belirlenmiştir.

valanga/ çı̆

İt. valanga sözcüğ̈̈nün "bir arada bulunan çok sayıda nesne veya olay" anlamında (GAB), örn., una valanga di proteste/ compiti/ notizie (protestolar/ ödevler/ haberler çığ gibi) (CORIS) şeklinde; Tr. çı̆̆ sözcüğünün "bir olayın birdenbire ve etkileyici bir biçimde büyümesi" anlamında (TDKG), örn., tepkiler çı̆̆ gibi, çı̆̆ gibi düşmek/ dökülmek/ büyümek (TUD) şeklinde kullanıldı̆̆ı belirlenmiştir.

fontana/ çeşme

İt. fontana sözcügünün "büyük miktarda madde" anlamında (GAB), örn., una fontana di pietra/farina (bir çeşme taş/ un) (CORIS) şeklinde; Tr. çeşme sözcüğünün "çok miktarda akışkan madde" anlamında çeşme gibi akmak benzetmesinde (TDK, s. 295), "çok ağlamak" anlamında iki gözü iki çeşme (TUD) şeklinde kullanıldığı görülmüştür.

onda, ondata/dalga

İt. onda, ondata sözcüklerinin "hareket eden büyük kitle, nicelik" anlamında (GAB), örn., un'onda di ricordi/ gioia (hatıra/ sevinç dalgası), un'ondata di vendite/ terrore (satış/ terör dalgası) (CORIS) şeklinde; Tr. dalga sözcüğünün "arka arkaya, yığın halinde gelen olaylar, nesneler" anlamında (TDKG), örn., kriz/ zam dalgası, dalga dalga çoğalmak/ gelmek (TUD) şeklinde kullanıldığı belirlenmiştir.

\subsection{Belirsiz Azlık İfadelerinde Kullanılan Adlar}

Belirsiz azlık ifadelerinde kullanılan adlar ve bu adların niceliği ifade edilecek varlık veya kavram adlarıyla bir araya gelerek oluşturdukları yapılara ilişkin örnekler aşağıdaki alt başlıklarda belirtilen anlamsal alanlara göre verilmektedir.

a. Belirsiz Azlık Belirten Küçük ve Sınırlı Yüzey Adları

fazzoletto/ peçete

İt. fazzoletto sözcüğünün "küçük bir yüzey veya alan" anlamında (GAB), örn., un fazzoletto di terra/ verde/ deserto (bir peçete arazi/ yeşillik/ çöl) (CORIS) şeklinde kullanıldığı; Tr. peçete sözcüğünün "belirsiz azlık" anlamında kullanılmadığı görülmüştür. 
palmo/ avuç

İt. palmo sözcüğünün "az sayıda, çok az" anlamında (GAB), örn., un palmo di spazio/ distanza (bir avuç alan/ mesafe) (CORIS) şeklinde; Tr. avuç sözcüğünün "az sayıda, çok az” anlamında (TDKG), örn., bir avuç insan/ şanslı (TUD) şeklinde kullanıldığı görülmüştür. Ayrıca Tr. avuç sözcüğünün "çokluk" anlamında kullanımı belirsiz çokluk ifadeleri başlığı altında açılanmıştır.

\section{b. Belirsiz Azlık Belirten Küçük Kitle veya Hacim Adları}

morso, boccone/ lokma

İt. morso, boccone sözcüklerinin "özellikle yiyecek olan bir şeyden bir ısırışta kopartılan parça kadar, bir bütünden parça” anlamında, örn., un morso della mela (bir lokma elma) (GAB), un boccone di terra (bir lokma arazi) (CORIS) şeklinde; Tr. lokma sözcügüüün "çok az" anlamında (TDKG), örn., bir lokma sevda/huzur (TUD) şeklinde kullanıldı̆̆ı görülmüştür.

sorso/ yudum

İt. sorso sözcüğünün "genelde sıvı için birazcık, çok az, bir yudumluk" anlamında (GAB), örn., un sorso di vino/ caffè (bir yudum şarap/ kahve) (CORIS) şeklinde; Tr. yudum sözcügünü̈ "çok az" anlamında (TDKG), örn., bir yudum anlayış/ insan/ şefkat (TUD) şeklinde kullanıldığı görülmüştür.

goccia/ damla

İt. goccia sözcüğünün "sıvı bir maddeden alınan en küçük miktar" anlamında, örn., una goccia di latte (bir damla süt); "çok az miktar" anlamında, örn., una goccia di buon senso (bir damla sağduyu) (GAB), una goccia di pioggia/ verità (bir damla yağmur/ gerçek) (CORIS) şeklinde; Tr. damla sözcüğünün "çok az" anlamında (TDKG), örn., bir damla ışık/ anlayış/ uyku (TUD) şeklinde kullanıldığı görülmüştür.

c. Belirsiz Azlık Belirten Küçük Parça veya Bölüm Adları

fetta/dilim

İt. fetta sözcügünün "bir niceliğin küçük bir bölümü" anlamında (GAB), örn., una fetta di potere/ spazio/ spettatori (bir dilim güç/ alan/ seyirci) (CORIS) şeklinde kullanıldı̆̆ı görülmüşsür. Tr. dilim sözcüğünün nicelik ifadelerinde kullanımına rastlanmamıştır.

\section{briciola/ kurntı}

İt. briciola sözcügünün "bir şeyin, bir niceliğin küçük bir kısmı” anlamında (GAB), örn., una briciola di tempo/ coraggio/ intelligenza (bir kurıntı zaman/ cesaret/ zeka) (CORIS) şeklinde; Tr. kurntı sözcüğünün "bir şeyden geriye kalan küçük bir miktar ve çok az" anlamlarında (TDKG), örn. bilgi/ zeka/ mutluluk/ sevgi kurıntıları (TUD) şeklinde kullanıldığı görülmüştür.

brandello/parça

İt. brandello sözcüğünün "çok küçük miktar" anlamında (GAB), örn., un brandello di informazione/ verità/ pudore (bir parça bilgi/ gerçeklik/ alçakgönüllülük) şeklinde (CORIS); Tr. parça sözcüğünün 
"biraz, azıcık, çok az" anlamında (TDKG), örn., bir parça teselli/ anlayış/ neşe/ mutluluk (TUD) şeklinde kullanıldı ̌̆ı görülmüştür.

grano, granello/tane, zerre

İt. grano, granello sözcüklerinin "bir bütünden alınan küçük bir parça, en az nicelik" anlamında (ZIN, s. 790), örn., un grano di spazio/ luce/ buon senso/ follia (bir tane alan/ ışı/ sağduyu/ çılgınlık) (CORIS) şeklinde; Tr. zerre sözcüğünün "çok küçük bir parçacık, çok az" anlamında (TDKG), örn., zerre kadar beyin/ iyilik/ merak/ endişe/ katkı (TUD) şeklinde kullanıldığı belirlenmiştir. Tr. tane sözcüğünün belirsiz nicelik ifadelerinde kullanılmadı̆̆g görülmüştür.

pizzico/tutam

İt. pizzico sözcügüüün "çok az" anlamında (REP), örn., un pizzico di fortuna/ esperienza/ gelosia/ curiosità (bir tutam şans/ deneyim/ kıskançlık/ merak) (CORIS) şeklinde; Tr. tutam sözcügünün "çok az" anlamında (TDKG), örn., bir tutam baharat/ mutluluk/ bahar/ vefa/ hürmet/ sıcaklık (TUD) şeklinde kullanıldığı görülmüştür.

\section{d. Belirsiz Azlık Belirten Küçük Nesne Adları}

capello, pelo/ saç, kal

İt. capello sözcü̈üünün "çok az, hiçbir şey” anlamında, örn., un capello di distanza/ vento (bir saç mesafe/ rüzgar) (CORIS); "bir şeyin olmasına çok az kaldı, yakın olma" anlamında, örn., manca un capello (bir saç kaldı), essere a un capello da qualcosa (bir şeye bir saç kaldı); İt. pelo sözcügünün "en az miktar, fark, algılanan en küçük mesafe” anlamında, örn., a un pelo dalla vittoria (zafere kıl payı) (GAB) şeklinde kullanıldığı; Tr. saç sözcüğünün nicelik ifadelerinde kullanılmadığı; Tr. kıl sözcüğünün "bir şeyin olamasına çok az kalmak" anlamında kul (kadar) kalmak, "hemen hemen, neredeyse" anlamında kıl payı (TDKG) kıl payı kurtulmak; "çok az" anlamında kıl payı bir fark var (TUD) şeklinde kullanıldığı görülmüştür.

\section{dito/parmak}

İt. dito sözcüğünün "parmak genişliğine eşit olan miktar ya da ölçü" anlamında, örn., un dito di vino/ sciroppo (bir parmak şarap/ şurup); "bir şeyden en az miktar" anlamında, örn. un dito di cervello (bir parmak beyin); "çok yakın, az kaldı" anlamında, örn., essere a un dito da qualcosa (bir şeye parmak kaldı) (GAB) şeklinde; Tr. parmak sözcügünün "az kaldı, az kalsın, neredeyse” anlamında parmak kaldı (TDKG), “az” anlamında bir parmak kahve/ mesafe (TUD) şeklinde kullanıldığı görülmüştür.

\section{Yorum}

Bulgular bölümünde belirsiz nicelik ifadelerinde kullanılan adlar anlamsal alanlarına göre incelenmiştir. Belirsiz çokluk ifadelerinde toplam 44 İtalyanca ve 33 Türkçe adın; belirsiz azlık ifadelerinde toplam 15 İtalyanca ve 10 Türkçe adın kullanıldığı belirlenmiştir. Belirlenen adların yer aldığı İtalyanca ve Türkçe nicelik ifadeleri anlamsal alanlara göre incelemesi, anlamsal ve yapısal incelemeleri aşağıda verilmektedir. 


\section{1. İtalyanca ve Türkçe Nicelik İfadelerinin Anlamsal Alanlara Göre İncelemesi}

Belirsiz çokluk ifadelerinde kullanılan adların anlamsal alanlara göre dağılımı şöyledir:

a. geniş alan ve yüzey adları: mare (deniz, derya); oceano (okyanus); mondo (dünya), lago (göl); foresta, bosco (orman);

b. dikey varlık adları: montagna (dă̆); mucchio, cumulo, barca (yı̆̆ın);

c. derin boşluk adları: subisso (uçurum);

d. kap ve büyük kap adları: sacco (çuval); vagone, carrozza (vagon, araba); scanalatura (oluk); grembo (kucak); palmo (avuç); fascio (tomar);

e. çok sayıda öğe içeren küme adları: esercito (ordu); batteria (batarya); reggimento (alay); battaglione (tabur, tümen); branco, gregge, sciame (sürü); carovana (kervan);

f. yönlü hareket eden varlık adları: torrente, fiume, fiumana (dere, ırmak, nehir); pioggia (yağmur); grandine (dolu); tempesta (firtina); bombardamento (bombardıman); nugolo (bulut); profluvio, diluvio, alluvione, inondazione (sel); caterva (tufan) massa, folla, ressa, calca (kitle, küme); invasione (istila); valanga (çı̆̆); fontana (çeşme); onda, ondata (dalga).

Bu adların arasında Tr. derya, deniz; İt. foresta, bosco (orman); İt. mucchio, cumulo, barca (yı̆̆ın); і̇t. branco, gregge, sciame (sürü); İt. profluvio, diluvio, alluvione, inondazione (sel); İt. torrente, fiume (dere, nehir) gibi eş anlamlı olanlar da bulunmaktadır. İtalyanca batteria, fiume, grandine, tempesta sözcükleri belirsiz çokluk ifadelerinde kullanılırken Türkçede sırasıyla karşılıkları olan batarya, ırmak/ nehir, dolu, firtına adlarının kullanılmadığı; Türkçe araba, oluk, kucak ve avuç adları belirsiz çokluk ifadelerinde kullanılırken İtalyancada sırasıyla karşlıkları olan carrozza, scanalatura, grembo, palmo adlarının kullanılmadığı; uçurum sözcüğ̈̈nün İtalyanca ve Türkçe nicelik ifadelerinde taşıdığı anlamın farklı olduğu; bunların dışındaki adların İtalyancada ve Türkçede aynı anlamda kullanıldığı görülmüş̧ür.

Belirsiz azlık ifadelerinde kullanılan adların anlamsal alanlara göre dağılımı şöyledir:

a. küçük ve sınırlı yüzey adları: fazzoletto (peçete); palmo (avuç);

b. küçük kitle veya hacim adları: morso, boccone (lokma); sorso (yudum); goccia (damla);

c. küçük parça veya bölüm adları: fetta (dilim); briciola (kurıntr); brandello (parça); grano, granello (tane, zerre); pizzico (tutam);

d. küçük nesne adları: capello, pelo (saç, kıl); dito (parmak).

İtalyanca fazzoletto, dilim, grano ve capello sözcükleri belirsiz azlık ifadelerinde kullanılırken Türkçede sırasıyla karşılıkları olan peçete, dilim, tane ve saç adlarının kullanılmadığı; Tr. avuç sözcüğünün hem çokluk hem de azlık ifadelerinde kullanıldığı görülmüştür.

İtalyanca ve Türkçe belirsiz nicelik ifadelerinin anlamsal ve yapısal incelemesi bulgular bölümündeki örnekler üzerinden yapılmış ve aşă̆ıda verilmektedir. 


\section{2. İtalyanca ve Türkçe Nicelik İfadelerinin Anlamsal İncelemesi}

Her iki dilde de, nicelik ifadelerinde kullanılan varlık adlarının başka somut canlı veya cansız varlık ya da soyut kavram adlarıyla bir araya gelerek oluşturdukları yapılarda anlam kaymasına uğrayarak nicelik ifade eder duruma geldikleri; örneğin, ad olan goccia/ damla sözcüklerinin soyut kavram adları olan buon senso/ sağduyu sözcükleriyle bir araya gelerek oluşturdukları una goccia di buon senso/ bir damla sağduyu şeklindeki nicelik ifadelerinde anlam kaymasına uğradıkları ve nicelik ifade eder duruma geldikleri görülmüştür. Bu bulgu, Aksenova'nın (2014) nicelik ifade eden adların anlam kaymasına uğradıklarına ilişkin görüşünü desteklemektedir.

Her iki dilde de, adların yer aldığı nicelik ifadelerinde niceliğin yanı sıra varlığın bazı nitel özellikleri de ifade edildiği; örneğin, montagna / dağ, cumulo/ yığın adlarının "dikeylik"; fiume/ dere adlarının "yatay hareketlilik"; onda, ondata/ dalga adlarının "art arda geliş”; invasione/ istila, valanga/ çı̆̆ adlarının "aniden ortaya çıkış"; grandine/ dolu, tempesta / firtına adlarının "şiddet, devamllık, gürültü”; nugolo/ bulut adlarının "yoğunluk" anlamları ifade ettikleri belirlenmiştir. Bu bulgu, Lukyanova'nın (1986), Rahilina ve Su-Hyon'un (2009) adların kullanılmasıyla niceliğinin yanında, varlığın bazı nitel özelliklerinin de belirtildiğine ilişkin görüşlerini desteklemektedir.

Belirsiz nicelik ifadelerinde genelde abartma söz konusudur ve nicelik belirtilirken konuşucunun duyguları ve değerlendirmeleri da yansıtılmaktadır. Örneğin, bir grubu ifade etmek için branco/ sürü sözcükleri kullanıldığında "küçümseme" anlamı da katılmaktadır; İt. carovana (kervan) sözcüğüyle "şaka yoluyla kalabalık ve gürültülü bir grup" ifade edilir. Bu bulgu, Ryabceva’nın (2000) belirsiz nicelik adlarla ifade edilirken duyguların da yansıtıldığına ilişkin görüşlerini desteklemektedir.

Olumlu veya olumsuz tümce içerisinde kullanımları açısından bakıldığında, adların yer aldığı belirsiz çokluk ve belirsiz azlık ifadelerinin olumlu tümcelerde kullanıldığı; olumsuz tümcelerde ise sadece belirsiz azlık ifadelerinin kullanıldığı belirlenmiştir. Belirsiz azlık ifadeleri herhangi bir varlığın ya da soyut kavramın sadece çok küçük bir kısmının varlığını ya da tamamen yokluğunu belirtebilir. Bir varlığın ya da soyut kavramın eksikliğinin, örn., İt. non avere una briciola d'intelligenza/ un dito di cervello (bir kırıntı zekaya/ bir parmak beyne sahip olmamak); Tr. bir kurntı bilgisi olmamak, bir damla anlayış göstermemek şeklinde oluşturulan ifadelerle belirtildiği görülmüştür.

Adların yer aldığı belirsiz nicelik ifadelerinin zaten bir abartma içerdikleri belirtilmişti, ancak adlara büyütme veya küçültme ekleri getirilerek ya da adlar tekrar edilerek bu ifadelerin verdiği anlamın daha da güçlendirildiği belirlenmiştir. İtalyancada örn., nugolo (bulut) sözcüğüne -one büyütme eki getirilerek oluşturulan nugolone, grano (tane) sözcüğüne -ello küçültme eki getirilerek oluşturulan granello; Türkçede, örn., damla, yudum sözcüklerine -cık, -cuk küçültme ekleri getirilerek oluşturulan damlacık, yudumcuk sözcüklerinin; adların çoğul kullanılmasıyla ya da tekrarlanmasıyla oluşturulan, örn., çuvallar dolusu ihbar, tomar tomar dolar şeklindeki yapıların nicelik ifadelerinin anlamlarını güçlendirmektedir.

\section{3. İtalyanca ve Türkçe Nicelik İfadelerinin Yapısal İncelemesi}

İtalyanca ve Türkçe belirsiz nicelik ifadelerinde yer alan adların, niceliklerini belirttikleri varlık veya kavram adlarıla bir araya gelerek oluşturdukları sözcük öbeklerinin yapıları incelenmiş ve şunlar saptanmıştır: 
1. İtalyancada nicelik ifade eden adların yer aldığı sözcük öbeklerinin yapısı genel olarak şu şekilde ifade edilebilir:

tanımlık $+\operatorname{ad} 1+$ di edatı $+\operatorname{ad} 2$

Bu yapıda nicelik ifade eden $a d 1$, niceliği ifade edilen ad2 öğesidir, örn., una montagna di libri (bir dă̆ kitap) ifadesi şu şekilde gösterilebilir:

tanımlık (una) + ad1 (montagna) + di edatı + ad2 (libri)

Genel yapının değişikliğe uğrayabildiği, yapıya başka öğelerin dahil edildiği, örn., belirsiz tanımlık yerine belirtili tanımlık, ad2 olarak ifade edilen adın önüne veya arkasına sıfatların getirildiği görülmüştür. İtalyanca belirsiz nicelik ifadelerinin yukarıda verilen genel yapısının, Türkçede ismin -in haline (Genetiv) ya da başka bir ifadeyle, tanımlığın belirsiz veya belirtili olmasına bağlı olarak belirtisiz ad tamlamasına veya belirtili ad tamlamasına denk geldiği söylenebilir.

2. Türkçede nicelik ifade eden adların yer aldığı sözcük öbeklerinin yapısı genel olarak şu şekilde ifade edilebilir

a. Belirtisiz ad tamlaması şeklindeki yapılar, adı (tamlayan) + ad2 (tamlanan) şeklinde ifade edilebilir, bu tür yapılarda nicelik ifade eden $a d 2$, niceliği ifade edilen ad1 öğesidir, örn.,

$\operatorname{ad} 1($ insan $)+\operatorname{ad} 2($ seli)

b. Benzetme edatı gibi getirilerek oluşturulan yapılar, ad1 + gibi + ad2 ya da ad $2+$ ad $1+$ gibi șeklinde ifade edilebilir, birinci yapıda ad2 tekil, ikinci yapıda ise çoğuldur. Bu tür yapılarda nicelik ifade eden ad1, niceliği ifade edilen ad2 öğesidir, örn.,

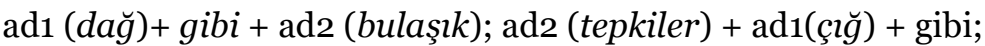

c. Karşılaştırma edatı kadar getirilerek oluşturulan yapılar; ad1 + kadar + ad2 şeklinde ifade edilebilir, bu tür yapılarda nicelik ifade eden $a d 1$, niceliği ifade edilen $a d 2$ öğesidir, örn.,

$\operatorname{ad} 1($ zerre $)+k a d a r+\operatorname{ad} 2($ anlayıss)

d. Dolusu sözcüğü getirilerek oluşturulan yapılar, ad1 + dolusu + ad2 şeklinde ifade edilebilir, bu tür yapılarda nicelik ifade eden $a d 1$, niceliği ifade edilen $a d 2$ öğesidir, örn.,

$\operatorname{ad} 1(k u c a k)+$ dolusu $+\operatorname{ad} 2($ sevgi $)$

e. Bir sayısı getirilerek oluşturulan yapılar, bir + ad1 + ad2 şeklinde ifade edilebilir, bu tür yapılarda nicelik ifade eden $a d 1$, niceliği ifade edilen $a d 2$ öğesidir, örn.,

$b i r+\operatorname{ad} 1(a v u c ̧)+\operatorname{ad} 2($ insan $)$

f. Adların tekrar edilmesiyle oluşturulan yapılar, ad1 + ad1 + ad2 ya da ad2 + ad1 + ad1 şeklinde ifade edilebilir, bu tür yapılarda nicelik ifade eden $a d 1$, niceliği ifade edilen $a d 2$ öğesidir, örn.,

$\operatorname{ad} 1($ tomar $)+\operatorname{ad} 1($ tomar $)+\operatorname{ad} 2($ para $) ; \operatorname{ad} 2($ zamlar $)+\operatorname{ad} 1($ dalga $)+\operatorname{ad} 1$ (dalga) 


\section{Sonuç}

İtalyanca ve Türkçe açıklamalı sözlüklerin ve derlemlerin taranması sonucunda tespit edilen belirsiz nicelik ifadelerindeki adların her iki dilde de yaygın olarak kullanıldığı görülmüştür. Varlık adları içeren nicelik ifadelerinin imgesellikleri nedeniyle etkili bir anlatım aracı oldukları, niceliğin yanında nitel değerlendirme de içerdikleri, konuşucunun duygularını ve abartılarını yansıttıkları; kültürel bilgi kaynakları oldukları söylenebilir.

Anlamsal alanlara göre incelenen adların her iki dilde de belirsiz çokluk veya belirsiz azlık bildiren nicelik ifadelerinde kullanıldığı, aralarında benzerliklerin ve farklılıkların bulunduğu görülmüştür. İtalyanca nicelik ifadelerinde kullanılan adların sayısının Türkçe adların sayısına göre daha fazla olduğu; İtalyanca nicelik ifadelerinde kullanılan adların yanı sıra bu adların eş anlamlılarının da yaygın olarak kullanıldığı görülmüsstür. Nicelik ifadelerinde anlamı güçlendirmek amacıyla İtalyancada büyütme ve küçültme ekleri, Türkçede küçültme ekleri ve sözcük tekrarları; her iki dilde adların yer aldığı belirsiz azlık ifadelerinin olumsuz anlamda da kullanıldığı belirlenmiştir.

İnceleme sonucunda İtalyanca ve Türkçe belirsiz nicelik ifadelerinin yapısal farklılıklar gösterdikleri görülmüştür. İtalyanca nicelik ifadeleri genel bir yapıya göre oluşturulurken, Türkçede bu yapıların belirtisiz ad tamlaması, benzetme, karşılaştırma şeklinde ve belli sözcüklerin kullanımı ve adların tekrarı ile oluşturulduğu görülmüş̧ür.

İtalyanca adların çok daha fazla varlık veya kavram adıyla bir araya gelerek, daha esnek nicelik ifadeleri oluşturdukları; Türkçe adların daha az sayıda varlık veya kavram adıyla bir araya gelerek, daha kalıplaşmış nicelik ifadeleri oluşturdukları söylenebilir.

Bu çalışmada ulaşılan bulgu ve sonuçlar yabancı dil olarak Türkçe ve İtalyanca öğretiminde öğrencilerin, belirsiz nicelik ifadelerini daha iyi anlama ve kullanma becerilerini, kavramların dildeki ifadelerinin incelenmesinde karşılaştırmalı bir bakış açısı geliştirmelerine katkı sağlayabilir. Açıklamalı sözlükler ve derlemler dikkate alınarak yapılan bu çalışma, edebi eserler incelenerek ve nicelik kavramının ifadesinde adların dışında kullanılan diğer sözcük türleri üzerine yapılabilecek araştırmalarla genişletilebilir.

\section{Kaynakça}

Aksan, Y. et al. (2012). Construction of the Turkish National Corpus (TNC). In Proceedings of the Eight International Conference on Language Resources and Evaluation (LREC 2012). İstanbul. Turkiye. 5 Aralık 2017 tarihinde http://www.lrec-conf.org/proceedings/lrec2012/papers.html adresinden erişildi.

Aksenova, K. A. (2014). Osobennosti Kachestvenniyh Parametrov i Sintakticheskogo Povedeniya Kvantifikatorov Neopredelyonno Bolšogo i Neopredelyonno Malogo Kolichestva v Sovremennom Angliyskom Yazıyke. Filologicheskiye Nauki. Voprosiy Teorii i Praktiki, 2 (32), II, 13-18.

Akulenko, V.V, Švachko, S.A., Bukreeva, E.İ ve diğerleri. (1990). Kategoriya Kolichestva $v$ Souremenniyh Evropeyskih Yazıykah. Kiev: Naukova Dumka.

Alekseyeva, E. N. (2003). Reprezentacia Koncepta "Neopredelennoe Mnojestvo" İmenami Suštestvitelnumi v Sovremennom Angliyskom Yazıyke. Doktora tezi, BGUEP, İrkutsk.

Arutyunova, N. D. (2005). Problema Chisla. N. D. Arutyunova (Ed.), Logicheskiy Analiz Yazıyka. Kvantitativnıy Aspekt Yazıyka içinde (ss. 6-21). Moskva: İndrik. 
Bordyugova, K. A. (2015). Osobennosti Grammatikalizacii Predmetnıyh İmen-Kvantifikatorov Neopredelenno-Mologo Kolichestba (Na Materiale Francuzskogo i Russkogo Yazıykov). Vestnik Cherepoveckogo Gosudarstvennogo Universiteta, 8, 41- 44.

Corpus CORIS. 5 Aralık 2017 tarihinde http://corpora.dslo.unibo.it/TCORIS/ adresinden erişildi.

Corriere della Sera. Dizionario di Italiano. 20 Temmuz 2017 tarihinde http://dizionari.corriere.it/dizionario_italiano/adresinden erişildi.

Gabrielli, A. (2011). Grande Dizionario Italiano. Hoepli.it. 20 Temmuz 2017 tarihinde http://www.grandidizionari.it/Dizionario_Italiano.aspx adresinden erişildi.

Galich, G. G. (2002). Kognitivnaya Kategoriya Kolichestva i Eyo Realizaciya v Sovremennom Nemeckom Yazıke. Omsk: OmGU.

Kochergo, D. C. (2014). Viyrajenie Kategorii Kvantitativnosti v Metaforah Neopredelennogo Mnojestva v Belorusskom Yazıyke. Vesnik MDPU, 96-100.

Kuzina, İ. Y. (2014). Kategoriya Kolichestva i Eyo Viyrajeniye v Yazıyke (Vvedenie v Problematiku). Magister Dixat, 1 (13), 108- 117.

La Repubblica.it. (2011). Dizionario di Italiano dalla A alla Z. Hoepli. 20 Temmuz 2017 tarihinde http://dizionari.repubblica.it/italiano.php adresinden erişildi.

Lukyanova, A. İ. (1986). Leksiko-Semanticheskaya Gruppa Obrazıy Mnojestva. A. İ. Lukyanova (Ed.), Ekspressivnaya Leksika Rasgovornogo Upotrebleniya içinde (ss. 123-138). Novosibirsk: Nauka.

Panfilov, V. Z. (1977). Filosofskie Problemıy Yazıykoznaniya. Moskva: Nauka.

Rahilina E. V., Su-Hyon, L. (2009). Semantika Leksicheskoy Mnojestvennosti v Russkom Yazıyke. Voprosiy Yazıykoznaniya, 4, 13- 40.

Ryabceva, N. K. (2000). Razmer i Kolichestvo v Yazıykovoy Kartine Mira. N. D. Arutyunova (Ed.), Logicheskiy Analiz Yazıyka. Yazıyki Prostranctv içinde (ss. 108-116). Moskva: Yazıyki Rus. Kulturiy.

Sergeyev, V. A. (1996a). O Kolichestvennoy Metafore. Russkaya rech, 4, 63- 66.

Sergeyev, V. A. (1996b). Kategoriya Kolichestva i Osobennosti Eyo Viyrajeniya v Yazıyke Publicistiki. Doktora tezi, MGU, Moskva.

Turaeva, Z. Y., Birenbaum, Y. G. (1985). Nekotoriye Osobennosti Kategorii Kolichestva. Voprosiy Yazıykoznaniya, 4, 122-130.

Türk Dil Kurumu. Güncel Türkçe Sözlük. 20 Temmuz 2017 tarihinde http://www.tdk.gov.tr/index.php?option=com_gts adresinden erişildi.

Türk Dil Kurumu. (1988). Türkçe Sözlük. Ankara: Türk Dil Kurumu.

Zingarelli, N. (1996). Vocabolario della Lingua Italiana (12. bs.). Bologna: Zanichelli. 